\title{
An Individual with Gastric Schwannoma with Pathologically Malignant Potential Surviving Two Years after Laparoscopy-Assisted Partial Gastrectomy
}

\author{
Akira Watanabe $^{a}$ Hitoshi Ojima $^{b}$ Shigemasa Suzuki ${ }^{a}$ \\ Yasushi Mochida $^{b}$ Isao Hirayamab ${ }^{b}$ Yasuo Hosouchib

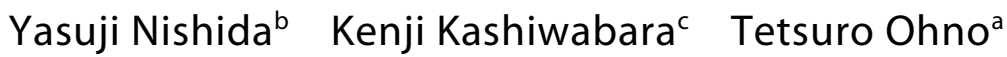 \\ Erito Mochiki ${ }^{a}$ Hiroyuki Kuwano ${ }^{a}$ \\ aDepartment of General Surgical Science, Gunma University Graduate

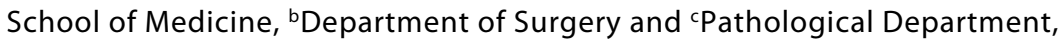 \\ Gunma Prefecture Saiseikai-Maebashi Hospital, Maebashi, Japan
}

\section{Key Words}

Gastric schwannoma · Malignant - Laparoscopy-assisted partial gastrectomy · No recurrence

\begin{abstract}
Schwannomas are a kind of neurogenic tumor. They are generally benign and originate primarily from the central and peripheral nerve. They rarely develop in the gastrointestinal tract: gastric schwannomas make up $0.2 \%$ of gastric neoplasms. A malignant gastric schwannoma is a comparatively rare tumor, a few cases have been reported until now. We present the case of a 34-year-old male patient diagnosed during medical examination. The patient was treated with surgical resection, and 2 years passed without recurrence.
\end{abstract}

\section{Introduction}

Schwannomas are rare among the spindle cell mesenchymal tumors of the digestive tract. They arise from Schwann cells of the neural plexus of the gastrointestinal wall [1]. Schwannomas make up approximately $0.2 \%$ of all gastric neoplasm. The tumors are usually benign, in some cases malignant [2]. Upper endoscopy is important in the evaluation on such tumors. However, on preoperative examination, it is difficult to 
discriminate a schwannoma from other submucosal tumors. Pathologically, in a schwannoma, immunostaining is positive for the S-100 protein and negative for c-KIT, actin, desmin, and CD34. The treatment is surgical resection. However, malignant cases often develop liver metastasis and peritoneal dissemination and have poor prognoses.

Presented here is the case of a 34-year-old male with a schwannoma; after partial gastrectomy had been performed, there was no recurrence for 2 years.

\section{Case Report}

A 34-year-old male had an abnormal shadow detected in an examination of the upper gastrointestinal tract. He did not have any other clinical complaints and previous history. A barium meal showed an elevated lesion extended at the greater curvature of the gastric body. Gastrointestinal endoscopy showed an ulcerated submucosal mass at the greater curvature of the gastric body (ig. 1 ). The biopsy at the lesion was diagnosed as a submucosal tumor of spindle cell morphology such as a gastrointestinal stromal tumor (GIST), leiomyoma or neurogenic tumor. Computed tomography of the abdomen revealed a $2 \mathrm{~cm}$ mass at the greater curvature of the gastric body and splenomegaly. There was no evidence of metastasis or enlarged lymph nodes. As noted above, we diagnosed a submucosal tumor of the gastric body and performed a laparoscopy-assisted partial gastrectomy. The mass had elasticity, solidity and ulceration. There was no abnormality in the surrounding organs or lymph nodes. The tumor measured $19 \times 18 \mathrm{~mm}(\underline{\text { fig. }}$ ) ). The patient had a complication-free postoperative course and was discharged 8 days following surgery. Immunohistochemically, the tumor was positive for the S-100 protein and negative for c-KIT, CD34, desmin and actin. The tumor had spindle cell morphology and an active mitotic shape (fig. 3). It was pathologically diagnosed as a malignant gastric schwannoma. After discharge from the hospital, the patient was examined every 3 months by computed tomography or gastrointestinal endoscopy; there has been no recurrence for 2 years.

\section{Discussion}

Gastric schwannomas represent $0.2 \%$ of all gastric tumors $[3,4]$. The patients are usually asymptomatic, and the tumors are detected during examinations. The patients may present with symptoms of abdominal pain or abdominal distension. Computed tomography, magnetic resonance imaging and gastrointestinal endoscopy are all useful in the diagnosis of gastric schwannomas. Computed tomography is helpful to define the exact location and extent of the tumor with displacement of surrounding organs. The schwannoma was visualized homogeneously and sharply marginated by computed tomography [5]. In magnetic resonance imaging, the overall signal pattern was low in T1-weighted images and moderate to markedly elevated in T2-weighted images [6]. Gastrointestinal endoscopy can be used to evaluate the size and location of a tumor. Typically, a schwannoma presents as a submucosal tumor. However, if a tumor presents ulceration, it is possible to achieve a pathological evaluation of the tumor by biopsy [7]. The pathological appearance is of whorled bundles of spindle-shaped cells with hyperchromatic nuclei (H\&E stain). Immunohistochemically, positive staining for S-100 protein and vimentin and negative staining for c-KIT, actin, desmin, and CD34 assist in the diagnosis of a schwannoma $[8,9]$. Malignant schwannomas are very rare, and about 20 cases have been reported in Japan [8]. In advanced cases, the tumor metastasizes to the liver and disseminates to the peritonea. However, the tumor does not metastasize to the lymph nodes. Surgical treatment is the exclusive method for treating a malignant schwannoma because chemotherapy and radiation are ineffective therapies [10]. 
With regard to small nonmetastatic schwannomas, it is difficult to determine the malignant potential of such tumors. FDG-PET is accepted as a powerful and noninvasive metabolic imaging modality for the evaluation of various tumors. Kamiyama et al. reported that FDG uptake and the malignant potential of gastric GISTs had a significant correlation [11]. However, in the case of schwannoma, benign tumors show higher FDG uptake [12]. Therefore, it is assumed that the evaluation of the malignant potential of a schwannoma by FDG uptake is inefficient. In this case the schwannoma was a nonmetastatic $2 \mathrm{~cm}$ in size; however, it has pathologically higher cell proliferation, abdominal mitosis, cellular atypia and invasion. Therefore, the potential of malignancy was pathologically indicated. The schwannoma in our case report was removed during a partial gastrectomy, and 2 years have passed without recurrence despite its pathologically malignant potential. The absence of recurrence is attributed to the size of the schwannoma. In fact, the size of the tumor may be linked to the potential for malignancy in GISTs. Local excision is necessary for the surgical removal of a schwannoma. Laparoscopy-assisted or laparoscopic resections are assumed to be suitable as minimally invasive surgical procedures.

In conclusion we have reported a case of gastric schwannoma with pathologically malignant potential. In this case, 2 years have passed without recurrence since the laparoscopy-assisted resection.

\section{Disclosure Statement}

The authors have no conflict of interest. 


\begin{tabular}{r|l|l|l}
$\begin{array}{r}\text { Case Reports in } \\
\text { Gastroenterology }\end{array}$ & $\begin{array}{l}\text { Case Rep Gastroenterol 2011;5:502-507 } \\
\text { DOI: 10.1159/000331561 }\end{array}$ & $\begin{array}{l}\text { Published online: } \\
\text { August 30, 2011 }\end{array}$ & $\begin{array}{l}\text { O 2011 S. Karger AG, Basel } \\
\text { ISSN 1662-0631 } \\
\text { www.karger.com/crg }\end{array}$ \\
\hline
\end{tabular}

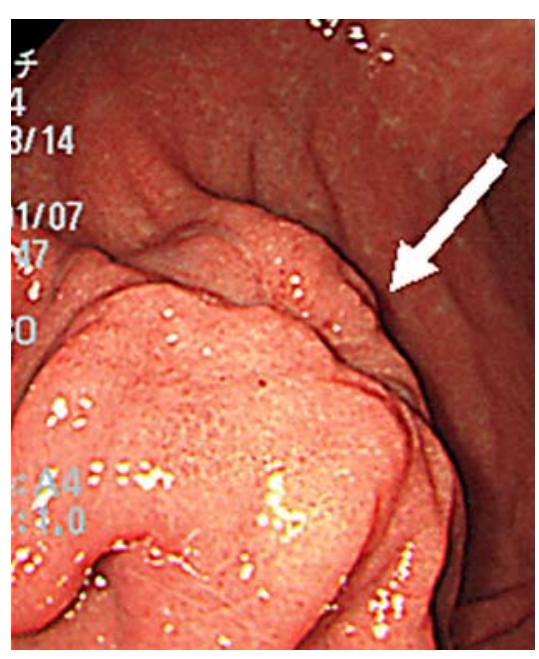

Fig. 1. Endoscopy picture showing the ulcerated submucosal mass (arrow) at the greater curvature of the gastric body.

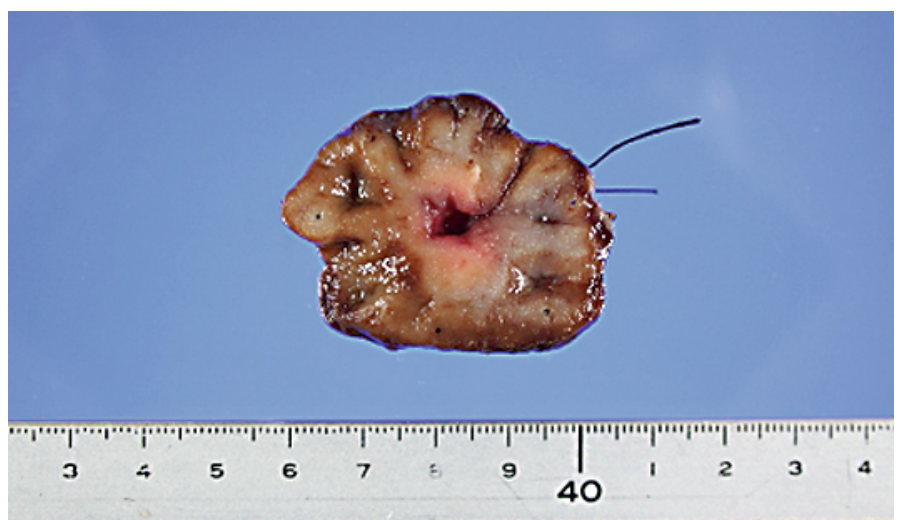

a

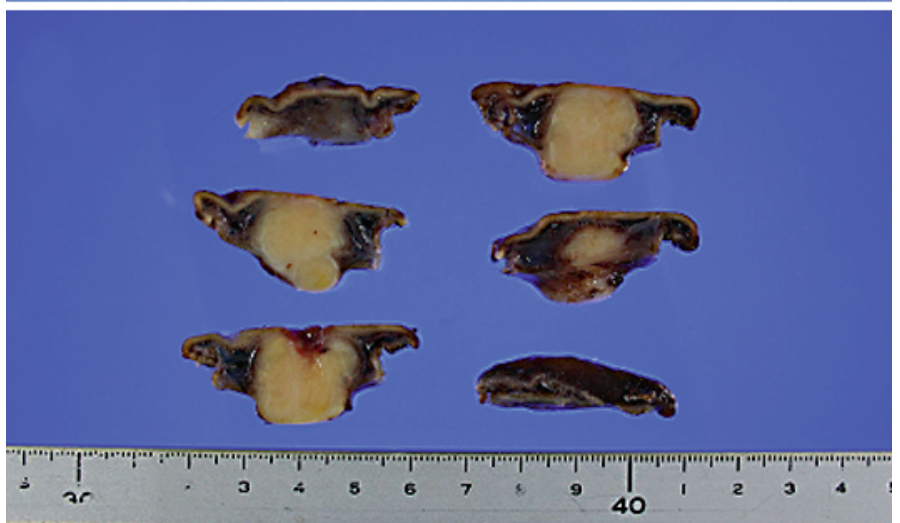

(b)

Fig. 2. a Excised specimen of the tumor. b Coronal section of the tumor. 


\begin{tabular}{r|l|l|l}
$\begin{array}{l}\text { Case Reports in } \\
\text { Gastroenterology }\end{array}$ & $\begin{array}{l}\text { Case Rep Gastroenterol 2011;5:502-507 } \\
\text { DOI: 10.1159/000331561 }\end{array}$ & $\begin{array}{l}\text { Published online: } \\
\text { August 30, 2011 }\end{array}$ & $\begin{array}{l}\text { O 2011 S. Karger AG, Basel } \\
\text { ISSN 1662-6031 } \\
\text { www.karger.com/crg }\end{array}$ \\
\hline
\end{tabular}

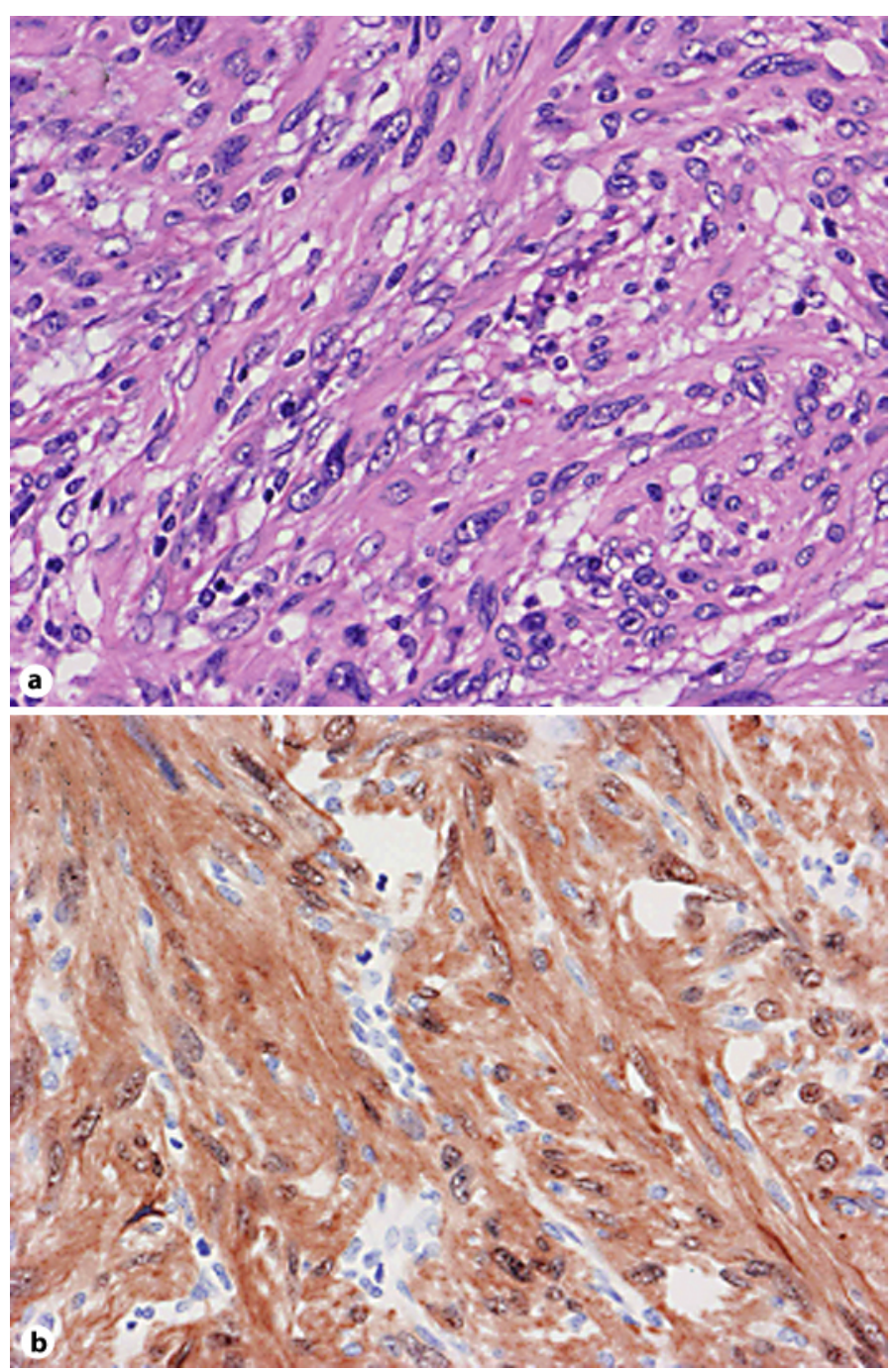

Fig. 3. a Hematoxylin-eosin staining $(\times 200)$. b Immunohistochemical staining positive to S-100 protein $(\times 200)$.

\section{References}

1 Miettinen M, Lasota J: Gastrointestinal stromal tumors - definition, clinical, histological, immunohistochemical, and molecular genetic features and differential diagnosis. Virchows Arch 2001;438: $1-12$.

2 Bees NR, Ng CS, Dicks-Mireaux C, Kiely EM: Gastric malignant schwannoma in a child. Br J Radiol 1997;70:952-955.

-3 Melvin WS, Wilkinson MG: Gastric schwannoma. Clinical and pathologic consideration. Am Surg 1993;59:293-296.

4 Daimaru Y, Kido H, Hashimoto H, Enjoji M: Benign schwannoma of the gastrointestinal tract: A clinicopathologic and immunohistochemical study. Hum Pathol 1988;19:257-264.

-5 Levy AD, Quiles AM, Miettinen M, Sobin LH: Gastrointestinal schwannomas: CT features with clinicopathologic correlation. AJR Am J Roentgenol 2005;184:797-802.

6 Karabulut N, Martin DR, Yang M: Case report: Gastric schwannoma: MRI findings. Br J Radiol 2002;75: 624-626. 
7 Yoon HY, Kim CB, Lee YH, Kim HG: Gastric schwannoma. Yonsei Med J 2008;49:1052-1054.

$>8$ Weiss SW, Langloss JM, Enjinger FM: Value of S-100 protein in the diagnosis of soft tissue tumors with particular reference to benign and malignant Schwann cell tumors. Lab Invest 1983;49:299-308.

-9 Sasaki S, Yabana T, Abe T, et al: A case of gastric malignant schwannoma. Nippon Shokakibyo Gakkai Zasshi 1994;91:322-327.

10 Sordillo PP, Helson L, Hajdu SI, et al: Malignant schwannoma-Clinical characteristics, survival and response to therapy. Cancer 1981;47:2503-2509.

11 Kamiyama Y, Aihara R, Nakabayashi T, Mochiki E, Asao T, Kuwano H, et al: 18F-fluorodeoxyglucose positron emission tomography: Useful technique for predicting malignant potential of gastrointestinal stromal tumors. World J Surg 2005;29:1429-1435.

12 Ahamad AR, Watanabe H, Aoki J, Shinozaki T, Takagishi K: Schwannoma of the extremities. The role of PET in preoperative planning. Eur J Nucl Med 2001;28:1541-1551. 